\title{
A Surface Bloom Sampler (SUBS) for cyanobacteria and algae
}

\author{
Roberto BERTONI \\ CNR - ISE, Institute of Ecosystem Study, Largo Tonolli 50, 28922 Verbania, Italy \\ e-mail: r.bertoni@ise.cnr.it
}

\begin{abstract}
In surface blooms, cell density is not evenly distributed with depth but shows a vertical abundance gradient, dependent on the hydrodynamics of water body and on cell buoyancy. To sample reproducibly and quantitatively cyanobacteria and algae blooms a simple Surface Bloom Sampler (SUBS) was designed. This instrument collects a known volume of water at the air-water interface. The sampled layer can be adjusted, according to the expected depth of the bloom, from 4 to $20 \mathrm{~cm}$.
\end{abstract}

Key words: water sampler, quantitative sampling, cyanobacteria bloom

\section{INTRODUCTION}

The sampling of air-water interface in water bodies has received attention in the past since the surface tension force at the boundary was recognized to concentrate organic molecules and microorganisms in the surface microlayer. According to the literature, the surface microlayer is considered to have a total thickness ranging between 1 and $1000 \mu \mathrm{m}$, encompassing several other layers with different ecological, chemical and physical properties (Wurld \& Obbard 2004). The same Authors state that the layer with thickness $>1000 \mu \mathrm{m}$ should be referred to as surface water. In fact, in case of algal or cyanobacterial blooms, the accumulation of organisms at the sea or lake surface exceeds such limit.

The accumulation of millimetre-thin (5-10 mm) layers of cyanobacterial biomass at the air-water interface in lakes leads to significant gradients of oxygen and $\mathrm{pH}$ within these aggregates (Ploug 2008). In the case of cyanobacteria, able to regulate their buoyancy, the thickness of the blooms is strongly dependent upon the hydrodynamics of aquatic ecosystems. In quiet days with little wind mixing, buoyant cyanobacteria can float upwards forming surface blooms reaching very high population density, even if cyanobacteria were initially present in the water column at low concentrations only.

For instance, concentrating in a surface layer $1 \mathrm{~cm}$ thick, the cyanobacteria present in a $5 \mathrm{~m}$ deep uniformly mixed layer with a density of 1000 cells $\mathrm{mL}^{-1}$, would raise cell density to 500.000 cells $\mathrm{mL}^{-1}$ (Huisman et al. 2005).

For these reasons caution must be taken in sampling a surface bloom. The simple scraping of water surface with a bucket obviously destroys the bloom forming aggregates, diluting them in an unpredictable way which depends on the non-reproducible bucket handling. Moreover, the use of a conventional water sampler, designed to operate underwater, unavoidably excludes from the sample the layers closer to the air-water interface.

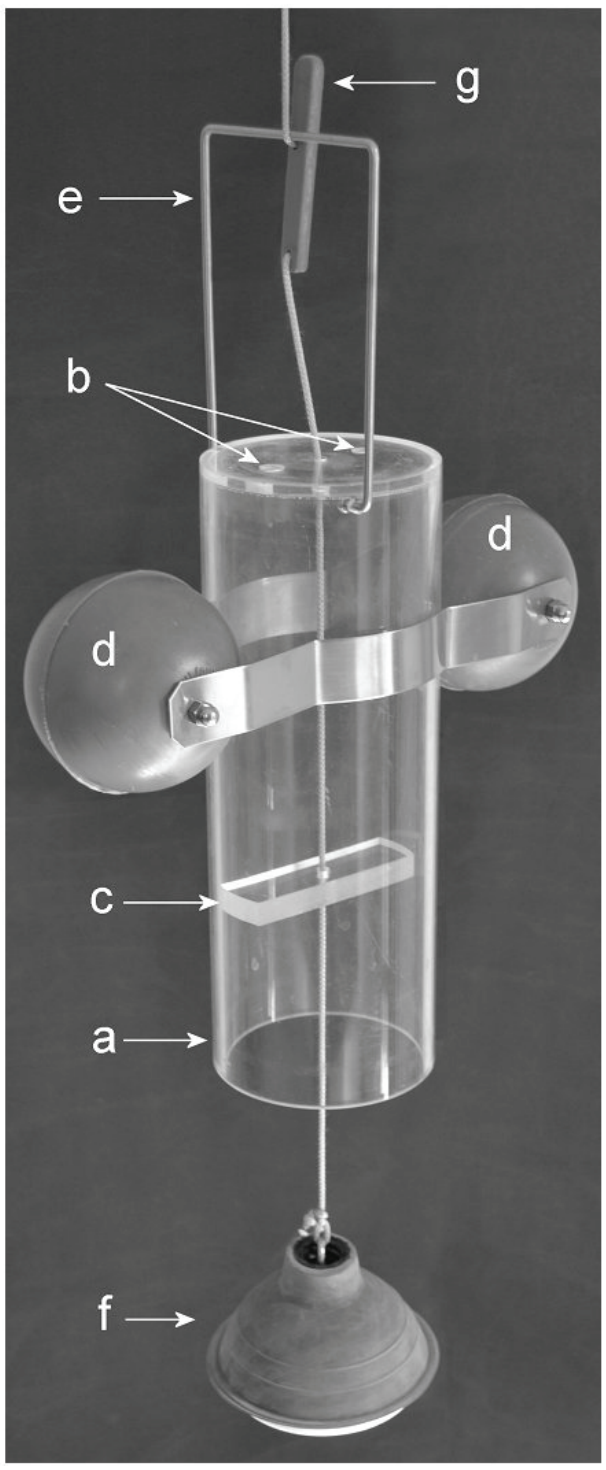

Fig. 1. Front view of the Surface Bloom Sampler (SUBS). Explanation in the text. 
The failure to determine quantitatively the true abundance of harmful algae or toxins in natural systems can be the source of dangerous bias when a legal obligation to verify the achievement of thresholds, considered critical for public health, must be fulfilled.

To solve the problem of sampling surface blooms in a reproducible way, a simple device that allows to take a water sample of known depth (and volume) at the airwater interface in water bodies was designed and tested. The sampled layer can be adjusted, according to the expected depth of the bloom, from 4 to $20 \mathrm{~cm}$.

\section{SAMPLER DESCRIPTION}

SUBS is made by a $300 \mathrm{~mm}$ long and $5 \mathrm{~mm}$ thick acrylic tube of $115 \mathrm{~mm}$ in diameter. The upper end is closed by a acrylic disc of $115 \mathrm{~mm}$ in diameter with a hole of $5 \mathrm{~mm}$ in diameter at the centre (Fig. 1a). Two opposite holes $(10 \mathrm{~mm}$ in diameter) are drilled at the right and left of the central hole and $30 \mathrm{~mm}$ from the outer edge of the disc (Fig. 1b). An acrylic bar with an hole $(5 \mathrm{~mm}$ in diameter) in the middle crossing the upper edge of the tube (Fig. 1e). A $2 \mathrm{~m}$ long nylon rope ( $3 \mathrm{~mm}$ diameter) passes across the holes $\mathrm{b}$ and $\mathrm{c}$, holding a non-floating conical rubber stopper (Fig. 1f). On the other end of the rope, a plastic hook is fixed (Fig. 1 g) to which the metallic handle is hanged before sampling. The distance between the plastic hook and the bottom stopper is of about $1 \mathrm{~m}$.

\section{SAMPLER OPERATION}

SUBS is hold from the upper edge of the rope, hanged to the hook. The bottom stopper is immersed in water and the lower mouth of the sampler is moved above a undisturbed area of the surface scum (Fig. 2, A). Then SUBS is lowered in the water until it starts floating, sustained by the two buoys. A further lowering of the rope unfastens the metallic handle that falls sideways (Fig. 2, B). Raising the rope moves the stopper to close the bottom of the acrylic tube when the sampler is pulled out of the water (Fig. 2, C). The sample of defined volume thus taken is then poured in bottles of convenient size for subsequent analysis.
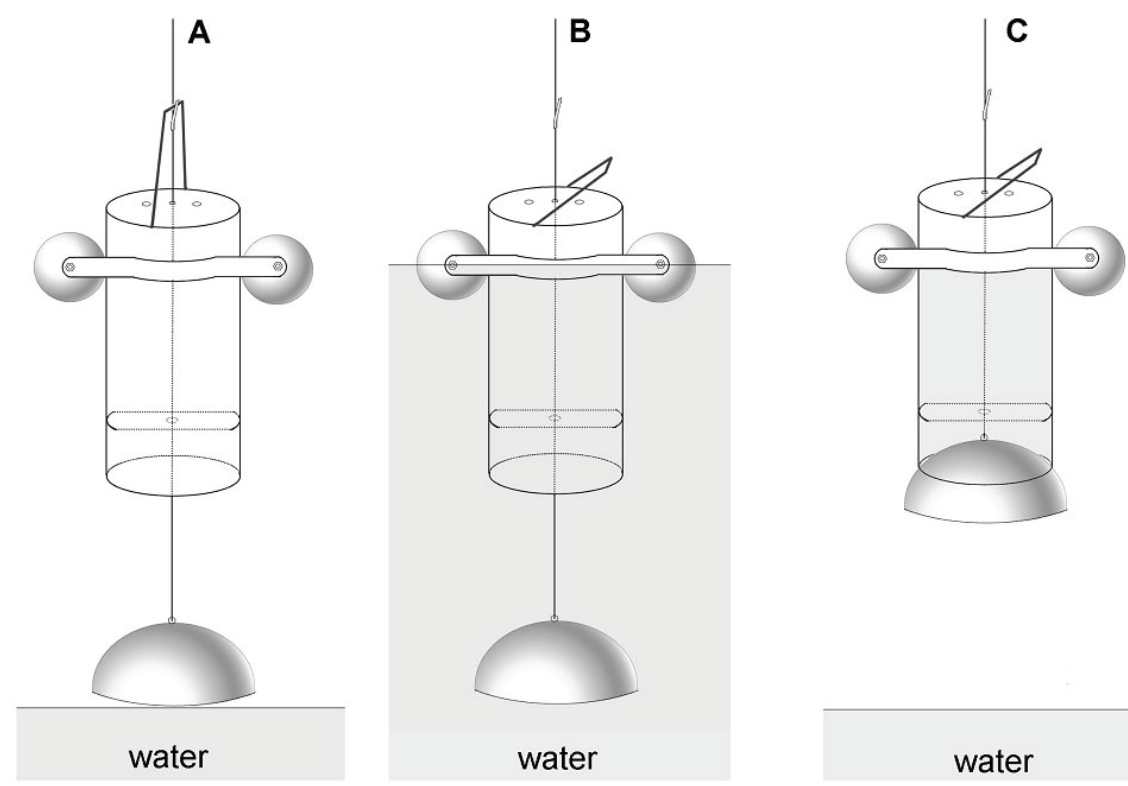

Fig. 2. Operation of Surface Bloom Sampler (SUBS). Explanation in the text.

inside of the tube along the diameter is fixed at $50 \mathrm{~mm}$ from the lower mouth of the tube (Fig. 1c). Outside the tube, near its upper end, there are two plastic spherical buoys (diameter $100 \mathrm{~mm}$ ), kept in place by a metallic frame made by two metal strips and two screws crossing the buoys along their diameter (Fig. 1d). The distance between the buoys and the sampler mouth can be adjusted to control the thickness of the layer sampled and the volume of water collected. A U-shaped metallic handle in stainless steel (5 $\mathrm{mm}$ diameter), pivots at the

\section{REFERENCES}

Huisman, J., H.C.P. Matthijs, P.M. Visser. 2005. Harmful cyanobacteria. Aquatic Ecology Series, Springer 241 pp.

Ploug, H. 2008. Cyanobacterial surface blooms formed by Aphanizomenon sp. and Nodularia spumigena in the Baltic Sea: Small-scale fluxes, $\mathrm{pH}$, and oxygen microenvironments. Limnol. Oceanogr., 53(3), 914-921.

Wurl, O., J.P. Obbard. 2004. A review of pollutants in the seasurface microlayer (SML): a unique habitat for marine organisms. Marine Pollution Bulletin, 48: 1016-1030. 